\title{
All about pain pharmacology: what pain physicians should know
}

\author{
Kyung-Hoon Kim ${ }^{1}$, Hyo-Jung Seo ${ }^{1}$, Salahadin $\mathrm{Abdi}^{2}$, and Billy Huh ${ }^{2}$ \\ 'Department of Anesthesia and Pain Medicine, School of Medicine, Pusan National University, Yangsan, Korea \\ ${ }^{2}$ Department of Pain Medicine, The University of Texas MD Anderson Cancer Center, Houston, TX, USA
}

Received February 8, 2020

Revised March 12, 2020

Accepted March 13, 2020

\section{Correspondence}

Kyung-Hoon Kim

Department of Anesthesia and Pain

Medicine, Pusan National University

Yangsan Hospital, 20 Geumo-ro,

Mulgeum-eup, Yangsan 50612, Korea

Tel: +82-55-360-1422

Fax: +82-55-360-2149

E-mail: pain@pusan.ac.kr
From the perspective of the definition of pain, pain can be divided into emotional and sensory components, which originate from potential and actual tissue damage, respectively. The pharmacologic treatment of the emotional pain component includes antianxiety drugs, antidepressants, and antipsychotics. The anti-anxiety drugs have anti-anxious, sedative, and somnolent effects. The antipsychotics are effective in patients with positive symptoms of psychosis. On the other hand, the sensory pain component can be divided into nociceptive and neuropathic pain. Non-steroidal anti-inflammatory drugs (NSAIDs) and opioids are usually applied for somatic and visceral nociceptive pain, respectively; anticonvulsants and antidepressants are administered for the treatment of neuropathic pain with positive and negative symptoms, respectively. The NSAIDs, which inhibit the cyclo-oxygenase pathway, exhibit anti-inflammatory, antipyretic, and analgesic effects; however, they have a therapeutic ceiling. The adverse reactions (ADRs) of the NSAIDs include gastrointestinal problems, generalized edema, and increased bleeding tendency. The opioids, which bind to the opioid receptors, present an analgesic effect only, without anti-inflammatory, antipyretic, or ceiling effects. The ADRs of the opioids start from itching and nausea/vomiting to cardiovascular and respiratory depression, as well as constipation. The anticonvulsants include carbamazepine, related to sodium channel blockade, and gabapentin and pregabalin, related to calcium blockade. The antidepressants show their analgesic actions mainly through inhibiting the reuptake of serotonin or norepinephrine. Most drugs, except NSAIDs, need an updose titration period. The principle of polypharmacy for analgesia in case of mixed components of pain is increasing therapeutic effects while reducing ADRs, based on the origin of the pain.

Key Words: Analgesics; Anticonvulsants; Antidepressive Agents; Anti-Inflammatory Agents, Non-Steroidal; Carbamazepine; Gabapentin; Neuralgia; Nociceptive Pain; Opioids; Polypharmacy; Pregabalin; Serotonin.

\section{INTRODUCTION}

Pain can be treated with invasive or non-invasive methods. Pharmacologic treatment, mostly systemic administration, uses non-invasive methods. Definite targeted invasive treatments, such as a percutaneous osteoplasty for metastasized bone fractures, or endoscopic discectomy for compressed nerves, have a definite advantage over broad-spectrum systemic analgesics in that they remove the source of the pain. If it is impossible to correct or remove the source of pain, non-invasive administration of systemic analgesics is the second choice. (a) This is an open-access article distributed under the terms of the Creative Commons Attribution Non-Commercial License (http://creativecommons.org/licenses/by-nc/4.0/), which permits unrestricted non-commercial use, distribution, and reproduction in any medium, provided the original work is properly cited.

(C) The Korean Pain Society, 2020
Author contributions: Kyung-Hoon Kim: Writing/manuscript preparation; Hyo-Jung Seo: Data curation; Salahadin Abdi: Writing/manuscript preparation; Billy Huh: Writing/manuscript preparation. 
Table 1. Classification of Pain and Recommendable Appropriate Analgesics

\begin{tabular}{|c|c|c|c|}
\hline Emotional pain & Anxiolytics (minor tranquilizers) & $\begin{array}{l}\text { Benzodiazepines } \\
\text { Etifoxine (etafenoxine) }\end{array}$ & Clonazepam, diazepam, midazolam \\
\hline & Antidepressants & $\begin{array}{l}\text { Typical } \\
\text { Atypical }\end{array}$ & $\begin{array}{l}\text { Nortriptyline, amitriptyline, } \\
\text { SSRIs, SSNRIs }\end{array}$ \\
\hline & Antipsychotics (major tranquilizers) & $\begin{array}{l}\text { First generation } \\
\text { Second generation }\end{array}$ & $\begin{array}{l}\text { Haloperidol, chlorpromazine } \\
\text { Quetiapine, risperidone, olanzapine }\end{array}$ \\
\hline Sensory pain & Nociceptive pain & $\begin{array}{l}\left.\text { Somatic (Superficial and deep }{ }^{a}\right) \\
\text { Visceral }^{a}\end{array}$ & $\begin{array}{l}\text { NSAIDs, APAP, ASA, and steroids } \\
\text { Opioids: weak and strong }\end{array}$ \\
\hline & Neuropathic pain & $\begin{array}{l}\text { Positive symptoms } \\
\text { Negative symptoms }\end{array}$ & $\begin{array}{l}\text { Anticonvulsants } \\
\text { Antidepressants: nortriptyline, amitriptyline }\end{array}$ \\
\hline
\end{tabular}

SSRIs: selective serotonin reuptake inhibitors, SSNRIs: selective serotonin norepinephrine reuptake inhibitors, NSAIDs: non-steroidal anti-inflammatory drugs, APAP: N-acetyl-para-aminophenol, ASA: acetyl salicylic acid.

${ }^{a}$ Deep somatic and visceral pain may present referred pain or radiating pain including radicular pain.

First of all, recognition of the source of the pain is the first step in choosing analgesics. When the origin of the pain is classified, it is preferable to use the International Association for the Study of Pain definition of pain [1]. Therefore, it can be divided into the emotional component, caused by potential tissue damage, and the sensory component, caused by actual tissue damage. The sensory component of pain is also divided into nociceptive (somatic and visceral) and neuropathic pain (positive and negative) (Table 1).

Somatic nociceptive pain, which can be divided into superficial and deep categories, shows a good response to non-steroidal anti-inflammatory drugs (NSAIDs), acetaminophen (Paracetamol ${ }^{\circledR}$, N-acetyl-para-aminophenol [APAP]), acetylsalicylic acid (ASA), and steroids. Visceral nociceptive pain usually responds to opioids. Deep nociceptive and visceral pain may sometimes present as referred pain and radiating pain, which create great confusion in deciding the origin of the pain.

Neuropathic pain can be divided into positive and negative symptom categories. Neuropathic pain with positive symptoms shows a good response to anticonvulsants, while neuropathic pain with negative symptoms responds well to antidepressants [2-5].

Most analgesics, except some which exhibit a therapeutic ceiling, such as NSAIDs, APAP, and ASA, need dose and dosage titration for seeking the appropriate analgesic blood level, which can control persistent pain, but not breakthrough pain.

The three steps for analgesic administration and pain management are pain relief at night, bed rest in the daytime, and active movement during daily life. In addition, the principle of polypharmacy is focused on increasing therapeutic effects (analgesia) while reducing adverse reactions (ADRs), based on the source of the pain.

This review provides appropriate choices of analgesics for the treatment of pain, based on the supposed origins of the pain.

\section{MAIN BODY}

\section{Sensory component of pain}

Nociceptive pain arises from actual or threatened damage to non-neural tissue, due to the activation of nociceptors. On the other hand, neuropathic pain is caused by a lesion or disease of the somatosensory nervous system, which exhibits abnormal function [6].

\section{1) Nociceptive pain}

Superficial somatic nociceptive pain exhibits well-demarcated, sharp, aching pain, while deep somatic nociceptive pain presents ill-demarcated, dull pain. Visceral pain shows poorly-demarcated, heavy, dull pain. Deep somatic and visceral nociceptive pain may have referred pain or radiating pain characteristics (including radicular pain).

Basically, the borders of the somatic and visceral structures are the dura in the head, the pleura and pericardium in the chest, the peritoneum in the abdomen, and the (potential) retroperitoneum (retroperitoneal space) behind the abdominal cavity in the pelvis.

Well-known referred pain from the visceral structures includes left shoulder pain from myocardial infarctions, and right supraclavicular pain from hepatobiliary disorders. Examples of representative referred pain from the deep somatic structures can be found in spinal joint pain from the atlanto-occipital and atlanto-axial joints, classic cervical, thoracic, and lumbar facet joints, and sacroiliac joints.

It has already been demonstrated that substance $\mathrm{P}$, calcitonin gene-related peptide, and protein gene product 9.5 containing nerve fibers, exist in the cervical facet joints in a cadaveric study [7]. This means that anti-inflammatory drugs may be effective through either systemic administration or local infiltration. Therefore, in the case of inflamed knee joints, as with the diarthrodial joints, it seems more effective to use direct intra-articular injections than 
innervating nerve branch blocks [8-10].

The medial branch also innervates bones, including the posterior lamina and spinous process, ligaments, including the supraspinous ligament, interspinous ligament, and ligament flavum, erect muscles, skin, and subcutaneous tissues, as well as the facet joints [11]. Therefore, the diagnostic value of medial branch blocks can be diluted, and the therapeutic effect may be lower than with facet joint injections.

\section{(1) Non-steroidal systemic analgesics}

\section{(1) NSAIDs}

The name NSAIDs includes analgesic drugs, which are not in the class of steroids and have an anti-inflammatory property. The NSAIDs reduce pain and inflammation, as well as fever. In addition, ASA also has the ability to reduce itching. However, APAP can only reduce pain and fever, not inflammation. Therefore, APAP is not an NSAID because it does not reduce inflammation. So, if there is inflammation, anti-inflammatory drugs which act by peripheral mechanisms are needed. Otherwise, if there is no inflammation, APAP, which acts on central mechanisms, can replace the NSAIDs.

The action mechanism of NSAIDs is usually explained by cyclo-oxygenase (COX). The COX is traditionally divided into the constitutive COX-1 isoform in the normal condition and the inducible COX-2 isoform in the inflammatory condition. However, controversially, the COX-1 and -2 isoforms are widely found in the human body, such as the central nervous system, peripheral nervous system, cardiovascular system, gastrointestinal system, endocrine system, and reproductive system under normal conditions. In addition, the COX-2 is especially found in the brain, kidney, and female reproductive system [12].

All currently available NSAIDs have 3 common representative therapeutic effects, namely, an analgesic, antiinflammatory, and antipyretic effect, and also have $3 \mathrm{com}$ mon representative ADRs, specifically gastric damage, renal damage, and an antiplatelet function. Therefore, it is better to choose and prescribe a familiar NSAID only for a short period of inflammation, while considering its halflife.

Common ADRs of NSAIDs in detail are (1) gastrointestinal problems related to gastrointestinal mucosa damage, due to decreased prostaglandin (PG) $\mathrm{E}_{2}$ resulting from COX-1 inhibition, such as dyspepsia, and gastric erosion, ulceration, perforation, and bleeding, (2) renal problems related to sodium and water retention, hypertension, and hemodynamic acute renal injury due to decreased PG $\mathrm{E}_{2}$ and $\mathrm{PGI}_{2}$, resulting from COX-1 and COX-2 inhibition, and
(3) cardiovascular and platelet aggregation problems, such as stroke and myocardial infarction due to decreased $\mathrm{PGI}_{2}$, resulting from greater COX-2 and lesser COX-1 inhibition, and increased bleeding tendency due to decreased thromboxane (TX) $\mathrm{A}_{2}$, resulting from COX-1 inhibition.

Relative COX-1 and COX-2 selectivity (COX-1/COX-2 half maximal inhibitory concentration $\left[\mathrm{IC}_{50}\right]$ value) for commonly used NSAIDs and ASA in order of value would be ketorolac, ketoprofen, indomethacin, ASA, naproxen, ibuprofen, piroxicam, meloxicam, diclofenac, celecoxib, valdecoxib, etoricoxib, rofecoxib, and lumiracoxib [13].

NSAIDs, APAP, and ASA have a ceiling effect, in which the fixed maximal therapeutic effect is achieved, but ADRs continue to worsen, as their doses increase. Finally, they increase the risk to benefit ratio, developing a ceiling effect.

\section{(2) ASA}

ASA has been commercially available from 1899 under the name Aspirin ${ }^{\circledR}$ (Bayer AG, Leverkusen, Germany). In addition to the 4 representative therapeutic effects already mentioned, a low dose of ASA has been used for reducing the risk of heart attack and stroke [14]. Long-term medication for at least 10-20 years may be effective in cancer prevention, especially with colorectal cancer [15], but also with endometrial [16], breast [17], and prostate cancer [18].

After Vane's discovery of COX in 1971, the mechanisms of action of non-opioid analgesics, including ASA, NSAIDs, and steroids, have been apparent $[19,20]$. However, ASA, unlike other NSAIDs, is known to produce a unique, irreversible inactivation of COX, since it covalently modifies both COX-1 and COX-2 by acetylating serine residue within the COX active sites. This irreversible inactivation of COX-1 results in a representative ADR, gastrotoxicity, ranging from gastritis to peptic ulcers and gastrointestinal bleeding [21-23].

In addition, COX-1 is the main form in the mature platelets in the blood, where it transforms arachnoid acid via the intermediates $\mathrm{PG} \mathrm{G} / \mathrm{H}$ to $\mathrm{TX}_{2}$ (vasoconstrictor and platelet activator). This inhibition of $\mathrm{TX}_{2}$ explains the antithrombotic properties of ASA [14,21-23].

There is a theory related to a clinical benefit in which ASA turns off COX-2's production of PGs, but switches on COX-2's ability to produce novel protective lipid mediators (ASA-triggered lipoxins). In other words, ASA, in a different way from NSAIDs, converts COX-2 into a protective mediator-generating system with anti-inflammatory and pro-resolving properties [23]. 


\section{(3) APAP}

APAP is used to treat pain and fever (but not inflammation or itching) after being synthetized in 1877 and being marketed as Tylenol ${ }^{\circledR}$ or Panadol $^{\circledR}$ in $1955[24,25]$. Its weak anti-inflammatory property is probably due to its poor effectiveness in high peroxide concentrations at the inflammatory site $[26,27]$.

As with ASA, which has a history of more than 100 years, the mechanism of action of APAP is still unclear. Potential analgesic mechanisms of APAP are (1) positive effects on the serotonergic descending inhibitory pain pathway, and (2) interactions with opioid systems, eicosanoid systems, and nitric oxide containing pathways $[27,28]$.

\section{(2) Steroids}

Steroids have the ability to inhibit both COX and lipoxygenase, resulting in a reduction of PGs and leukotrienes (LTs).

LTs are inflammatory mediators, and include the dihydroxy acid LT (LTB4) and the cysteinyl LTs (CysLTs; LTC4, LTD4, LTE4). The high-affinity LTB4 receptors are known as BLT1, the LTC4, and LTD4 receptors as CysLT1 and CysLT2, and the LTE4 receptors as GPR99. BLT1 signaling stimulates the degranulation, chemotaxis, and phagocytosis of neutrophils, and CysLT1 and CysLT2 signaling induces airway inflammation by bronchial smooth muscle contraction and increasing vascular permeability. Therefore, these LTs are involved in chronic inflammatory disorders, such as asthma, atopic dermatitis, psoriasis, atherosclerosis, arthritis, obesity, cancer, and age-related degeneration $[29,30]$.

Steroids in palliative care are indicated for special conditions, such as spinal cord compression, increased intracranial pressure, and bowel obstruction, and for responding to general conditions, such as reducing pain, stimulating appetite, suppressing nausea, and alleviating fatigue. Generally, inhibition of PG and LT synthesis by steroids leads to reducing pain, inflammation, and vascular permeability (edema) [31].

\section{(3) Opioids}

Opioids for analgesia have been used for over 5,000 years. Opioids are substances that acts on the opioid receptors, such as the mu, kappa, and delta receptors. According to the action on the opioid receptors, opioids can be divided into agonists, antagonists, and partial agonists/antagonists. Opioid agonists bind to G-protein coupled receptors, and cause cellular hyperpolarization [32].

Opioid up-titration may be needed due to cancer pro- gression from a visceral origin. However, in cases of newly-developed invasions into other structures, non-opioid analgesics are helpful to manage the somatic pain, and anticonvulsants and antidepressants are effective to control the neuropathic pain.

Opioids are effective for both somatic and visceral nociceptive pain; however, they should only be started in patients with chronic non-malignant disorders if physicians are confident, they can taper and then discontinue them. Extra caution should be used in giving immediate-release opioids to young patients with chronic non-malignant disorders, especially chronic pancreatitis (visceral pain), complex regional pain syndrome (neuropathic pain), or bony fracture (somatic pain). Thanks to the development of the diagnosis and treatment of cancer, patients who experience complete recovery from cancer may be candidates for opioid addiction.

Methadone was approved by the U.S. Food and Drug Administration in 1972 for the treatment of opioid addiction. It has 2 enantiomers found in equal amounts in a racemic mixture; the active $\mathrm{R}$ enantiomer has a half-life of 36-48 hours and the inactive S enantiomer has a half-life of approximately 16 hours. Therefore, it is rapidly absorbed by the oral route with a delayed onset of action (with peak level at 2-4 hr) and with sustained levels maintained over 24 hours. It also has N-methyl-D-aspartate (NMDA) receptor antagonist properties. The initial dose starts with 20 $40 \mathrm{mg} / \mathrm{day}$, then the dose is gradually increased by $10 \mathrm{mg}$ every 4-7 days [33].

Conventional opioids activate 2 intracellular signaling pathways: the $\mathrm{G}$ protein pathway induces analgesia, while the beta-arrestin pathway is responsible for the opioidrelated ADRs. An academically ideal oliceridine (TRV130) has been studied for its role in both activation of the $G$ protein pathway for analgesia and deactivating the betaarrestin pathway for reducing ADRs [34]. Clinicians await the launch of this novel opioid with lesser ADRs.

\section{2) Neuropathic pain}

Pharmacologic treatment of neuropathic pain begins from the translation of symptoms and signs in patients into the underlying mechanisms, and simply classifying them as positive or negative (Table 2) [2,5].

Representative negative sensory symptoms and signs in neuropathic pain (with their underlying mechanisms) are a reduced sensation of ( 1 ) touch (A $\beta$ fiber abnormalities), (2) vibration (A $\beta$ fiber abnormalities), (3) pin prick (A $\delta$ fiber abnormalities), and (4) cold and heat (A $\delta / C$ fibers abnormalities).

On the other hand, positive symptoms and signs can be divided into spontaneous or evoked pain according to the 
Table 2. Recognition of Neuropathic Pain: Sensory Symptoms and Signs of Neuropathic Pain, Clinical and Laboratory Tests, and Underlying Mechanisms

\begin{tabular}{|c|c|c|c|}
\hline Sensory symptom and sign & Bedside examination & Laboratory examination & Mechanism \\
\hline \multicolumn{4}{|c|}{ 1. Negative sensory symptoms and signs } \\
\hline 1) Reduced touch & Touch skin with cotton wool & Graded von Frey hair & $A \beta$ fibers \\
\hline 2) Reduced pin prick & Prick skin with a pin single stimulus & von Frey hair specific (e.g., 100-g) & A $\delta$ fibers \\
\hline 3) Reduced cold and warm & $\begin{array}{l}\text { Thermal response to cold and } \\
\text { warm objects }\left(20^{\circ} \mathrm{C} \text { and } 45^{\circ} \mathrm{C}\right)\end{array}$ & $\begin{array}{l}\text { Detection of pain threshold for } \\
\text { warm and cold objects }\end{array}$ & A $\delta / C$ fibers \\
\hline 4) Reduced vibration & $\begin{array}{l}\text { Tuning fork on the medial } \\
\text { malleolus }\end{array}$ & Vibrometer & A $\beta$ fibers \\
\hline \multicolumn{4}{|c|}{ 2. Positive sensory symptoms and signs } \\
\hline \multicolumn{4}{|l|}{ 1) Spontaneous pain } \\
\hline (1) Paresthesia & Grade $(0-10)$ & Area in $\mathrm{cm}^{2}$ grade $(0-10)$ & $\begin{array}{l}\text { Spontaneous activity in long-term } A \beta \\
\text { afferent fibers }\end{array}$ \\
\hline (2) Dysesthesia & Grade $(0-10)$ & Area in $\mathrm{cm}^{2}$ grade $(0-10)$ & $\begin{array}{l}\text { Spontaneous activity in } \mathrm{A} \delta / \mathrm{C} \text { afferent } \\
\text { fibers }\end{array}$ \\
\hline (3) Paroxysms & Grade (0-10) & Threshold for evocation & Spontaneous activity in $\mathrm{C}$ nociceptors \\
\hline (4) Superficial burning pain & Grade (0-10) & Area in $\mathrm{cm}^{2}$ grade $(0-10)$ & Spontaneous activity in $\mathrm{C}$ nociceptors \\
\hline (5) Deep pain & Grade (0-10) & Area in $\mathrm{cm}^{2}$ grade $(0-10)$ & $\begin{array}{l}\text { Spontaneous activity in joint/muscle } \\
\text { nociceptors }\end{array}$ \\
\hline \multicolumn{4}{|l|}{ 2) Evoked pain } \\
\hline (1) Touch evoked hyperalgesia & Stroking skin with brush & None & $\begin{array}{l}\text { Central sensitization: C fiber input } \\
\text { and loss of C fiber input }\end{array}$ \\
\hline (2) Static hyperalgesia & Gentle mechanical pressure & Evoked pain to pressure & Peripheral sensitization \\
\hline (3) Punctate hyperalgesia & Pricking skin with a pin & von Frey hair & $\begin{array}{l}\text { Central sensitization: A } \delta \text { afferent } \\
\text { fibers input }\end{array}$ \\
\hline $\begin{array}{l}\text { (4) Punctate repetitive } \\
\text { hyperalgesia (windup-like pain) }\end{array}$ & $\begin{array}{l}\text { Pricking skin with a pin } 60 \\
\text { times } / 30 \mathrm{sec}\end{array}$ & von Frey hair & $\begin{array}{l}\text { Central sensitization: A } \delta \text { afferent } \\
\text { fibers input }\end{array}$ \\
\hline (5) Aftersensation & $\begin{array}{l}\text { Measurement of pain duration } \\
\text { after stimulation }\end{array}$ & $\begin{array}{l}\text { Measurement of pain duration } \\
\text { after stimulation }\end{array}$ & Central sensitization \\
\hline (6) Cold hyperalgesia & $\begin{array}{l}\text { Stimulation skin with cool metal } \\
\text { roller }\end{array}$ & Evoked pain to cold stimuli & Central sensitization and disinhibition \\
\hline (7) Heat hyperalgesia & $\begin{array}{l}\text { Stimulation skin with warm metal } \\
\text { roller }\end{array}$ & Evoked pain to heat stimuli & Peripheral sensitization \\
\hline (8) Chemical hyperalgesia & Topical capsaicin & Topical capsaicin & Peripheral sensitization \\
\hline (9) Sympathetic maintained pain & Sympathetic blockade & Modulation of sympathetic outflow & Sympathetic afferent coupling \\
\hline
\end{tabular}

Reproduced from the article of Jensen and Baron (Pain 2003; 102: 1-8) [2].

absence or presence of stimuli. Spontaneous pain (and its underlying spontaneous activity) includes (1) paresthesia (low threshold $\mathrm{A} \beta$ afferents), (2) dysesthesia (A $\delta / \mathrm{C}$ afferents), (3) paroxysms (C-nociceptors), (4) superficial burning pain (C-nociceptors), and (5) deep pain (joint/muscle nociceptors). Evoked pain includes (1) touch evoked hyperalgesia (central sensitization related to $C$ fiber input), (2) static hyperalgesia (peripheral sensitization), (3) punctate hyperalgesia (central sensitization related to $\mathrm{A} \delta$ fiber input), (4) punctate repetitive hyperalgesia (windup-like pain, central sensitization related to $\mathrm{A} \delta$ fiber input), (5) aftersensation (central sensitization), (6) cold hyperalgesia (central sensitization and disinhibition), (7) heat hyperalgesia (peripheral sensitization), (8) chemical hyperalgesia (peripheral sensitization), and (9) sympathetic maintained pain (sympathetic afferent coupling). In summarizing positive neuropathic pain, spontaneous pain includes paresthesia, dysesthesia, paroxysms, superficial burning pain, and deep pain; evoked pain includes various kinds of hyperalgesia, aftersensation, and sympathetic maintained pain [5].

The representative evoked positive symptoms of neuropathic pain are mechanical (dynamic, punctate, and superficial or deep static) and thermal (cold and heat) hyperalgesia and allodynia [5].

Several available clinical assessment tools for neuropathic pain have been developed for evaluation of the neuropathic pain component ratio among patients' whole pain, and for comparison of neuropathic pain scores before and after non-invasive or invasive treatment. Common screening tools for neuropathic pain are (1) the neuropathic pain questionnaire (NPQ), (2) douleur neuropathique en 4 (DN4), (3) Leeds assessment of neuropathic symptoms and signs (LANSS), (4) ID pain, (5) painDETECT (Table 3), as well as (6) the neuropathic pain symptom inventory (NPSI) questionnaire (Table 4) [4,5,3542].

The NPQ includes 12 items scored from 0 to 100 and its coefficient: (1) burning $\times 0.006$, (2) overly sensitive to touch $\times 0.005$, (3) shooting pain $\times 0.005$, (4) numbness $\times 0.020$, 
Table 3. Summary of Various Neuropathic Pain Questionnaires

\begin{tabular}{|c|c|c|c|c|}
\hline NPQ [38] & DN4 [39] & LANSS [40] & ID pain [41] & painDETECT [42] \\
\hline 1. Burning $\times 0.006$ & Question $1^{a}$ & Pain questionnaires & $\begin{array}{l}\text { 1. Pins and needles (Yes: } \\
\text { 1, No: 0) }\end{array}$ & $\begin{array}{l}\text { 1. Grading of pain (0: never, } \\
\text { 1: hardly, 2: slightly, } 3 \text { : } \\
\text { moderately, 4: strongly, or } \\
\text { 5: very strongly noticed) }\end{array}$ \\
\hline $\begin{array}{l}\text { 2. Overly sensitive to touch } x \\
0.005\end{array}$ & 1. Burning & $\begin{array}{l}\text { 1. Dysesthesia (Yes: 5, No: } \\
\text { 0) }\end{array}$ & $\begin{array}{l}\text { 2. Hot/burning sensation } \\
\text { (Yes: 1, No: 0) }\end{array}$ & $\begin{array}{l}\text { 2. The pain course pattern } \\
\text { (0: persistent pain with } \\
\text { slight fluctuations, }-1 \text { : } \\
\text { persistent pain with pain } \\
\text { attacks, }+1 \text { : persistent } \\
\text { pain without pain between } \\
\text { attacks, or }+1 \text { : persistent } \\
\text { pain with pain between } \\
\text { attacks) }\end{array}$ \\
\hline 3. Shooting pain $\times 0.005$ & 2. Painful cold & $\begin{array}{l}\text { 2. Color change of the skin } \\
\text { in the painful area (Yes: } 5 \text {, } \\
\text { No: 0) }\end{array}$ & $\begin{array}{l}\text { 3. Numbness } \\
\text { (Yes: 1, No: 0) }\end{array}$ & $\begin{array}{l}\text { 3. Radiating pain (+2: yes, } \\
\text { or 0: no) }\end{array}$ \\
\hline 4. Numbness $\times 0.020$ & 3. Electric shocks & $\begin{array}{l}\text { 3. Abnormal sensitivity to } \\
\text { touch in the affected skin } \\
\text { (Yes: } 3, \text { No: 0) }\end{array}$ & $\begin{array}{l}\text { Electric shocks } \\
(\text { Yes: 1, No: 0) }\end{array}$ & $\begin{array}{l}\text { The total score varies from } 0 \\
\text { to } 8 \text {. }\end{array}$ \\
\hline 5. Electric pain $\times-0.008$ & Question $2^{\mathrm{a}}$ & $\begin{array}{l}\text { 4. Abnormal skin tempera- } \\
\text { ture change in the painful } \\
\text { area (Yes: } 2, \text { No: 0) }\end{array}$ & $\begin{array}{l}\text { Worsening with touch } \\
\text { (Yes: 1, No: 0) }\end{array}$ & \\
\hline 6. Tingling $\times 0.010$ & 4. Tingling & $\begin{array}{l}\text { 5. Abnormal skin tempera- } \\
\text { ture change (Yes: 1, No: } \\
\text { 0) }\end{array}$ & $\begin{array}{l}\text { Limited to the joints } \\
\text { (Yes: }-1, \text { No: } 0)\end{array}$ & \\
\hline 7. Squeezing $\times-0.004$ & 5. Pins and needles & The sensory testing & $\begin{array}{l}\text { The total score varies } \\
\text { from }-1 \text { to } 5 \text {. }\end{array}$ & \\
\hline 8. Freezing × 0.004 & 6. Numbness & 1. Allodynia (Yes: 5, No: 0) & & \\
\hline 9. Unpleasant $\times 0.006$ & 7. Itching & $\begin{array}{l}\text { 2. An altered pin-prick } \\
\text { threshold (Yes: } 3, \text { No: 0) }\end{array}$ & & \\
\hline 10. Overwhelming $\times-0.003$ & & $\begin{array}{l}\text { The total score varies from } 0 \\
\text { to } 24 \text {. }\end{array}$ & & \\
\hline $\begin{array}{l}\text { 11. Tactile hyperalgesia } \times \\
0.006\end{array}$ & Question $3^{\mathrm{b}}$ & $\begin{array}{l}\text { If the score }<12 \text {, neuropathic } \\
\text { mechanisms are unlikely } \\
\text { to be contributing to the } \\
\text { patient's pain. }\end{array}$ & & \\
\hline $\begin{array}{l}\text { 12. Increased pain due to } \\
\text { weather changes } \times-0.005\end{array}$ & $\begin{array}{l}\text { 8. Hypoesthesia to } \\
\text { touch }\end{array}$ & $\begin{array}{l}\text { If the score } \geq 12 \text {, neuropathic } \\
\text { mechanisms are likely to be } \\
\text { contributing to the patient's } \\
\text { pain. }\end{array}$ & & \\
\hline $\begin{array}{l}\text { If the total score minus } 1.408 \\
\text { is below } 0 \text {, it predicts non- } \\
\text { neuropathic pain. }\end{array}$ & $\begin{array}{l}\text { 9. Hypoesthesia to } \\
\text { pinprick }\end{array}$ & & & \\
\hline \multirow{2}{*}{$\begin{array}{l}\text { On the contrary, if the total } \\
\text { score minus } 1.408 \text { is at or } \\
\text { above } 0 \text {, it predicts } \\
\text { neuropathic pain. }\end{array}$} & Question $4^{\mathrm{b}}$ & & & \\
\hline & $\begin{array}{l}\text { 10. Pain caused by or } \\
\text { increased by brushing } \\
\text { Yes }=1 \text {, No }=0 \\
\text { Patient's score }=\square / 10\end{array}$ & & & \\
\hline
\end{tabular}

NPQ: neuropathic pain questionnaire, DN4: douleur neuropathique en 4, LANSS: Leeds assessment of neuropathic symptoms and signs.

${ }^{a}$ From interview of the patient. ${ }^{b}$ From examination of the patient.

(5) electric pain $\times-0.008$, (6) tingling $\times 0.010$, (7) squeezing $\times-0.004$, (8) freezing $\times 0.004$, (9) unpleasant $\times 0.006$, (10) overwhelming $\times-0.003$, (11) tactile hyperalgesia $\times 0.006$, and (12) increased pain due to weather changes $\times-0.005$. If the total score minus 1.408 is below 0 , it predicts nonneuropathic pain. On the contrary, if the total score minus 
Table 4. Neuropathic Pain Symptom Inventory Questionnaire

\begin{tabular}{|c|c|c|}
\hline Neuropathic pain symptom inventory & Interpretation of pain & Score \\
\hline Q1. Burning & Superficial spontaneous pain & $0-10$ \\
\hline Q2. Squeezing & Deep spontaneous pain & $0-10$ \\
\hline Q3. Pressure & & $0-10$ \\
\hline \multirow[t]{5}{*}{ Q4. Spontaneous pain during the past $24 \mathrm{hr}$} & & Permanently \\
\hline & & 8-12 hr \\
\hline & & 4-7 hr \\
\hline & & $1-3 \mathrm{hr}$ \\
\hline & & $<1 \mathrm{hr}$ \\
\hline Q5. Electric shocks & Paroxysmal pain & $0-10$ \\
\hline Q6. Stabbing & & $0-10$ \\
\hline \multirow[t]{5}{*}{ Q7. Pain attacks during the past $24 \mathrm{hr}$} & & > 20 times/day \\
\hline & & 11-20 times/day \\
\hline & & 6-10 times/day \\
\hline & & $1-5$ times/day \\
\hline & & 0 times/day \\
\hline Q8. Pain provoked by or increased by brushing on the painful area & Evoked pain & $0-10$ \\
\hline Q9. Pain provoked by or increased by pressure on the painful area & & $0-10$ \\
\hline Q10. Pain provoked by or increased by contact with something cold on the painful area & & $0-10$ \\
\hline Q11. Pins and needles & Paresthesia/Dysesthesia & $0-10$ \\
\hline Q12. Tingling & & $0-10$ \\
\hline \multicolumn{3}{|l|}{ Results } \\
\hline Total intensity score & Sub-scores & $0-100$ \\
\hline Q1 = Superficial spontaneous pain & $/ 1=0-10 \times 2$ & $0-20$ \\
\hline Q2 + Q3 = Deep spontaneous pain & $/ 2=0-10 \times 2$ & $0-20$ \\
\hline Q5 + Q6 = Paroxysmal pain & $/ 2=0-10 \times 2$ & $0-20$ \\
\hline Q8 + Q9 + Q10 = Evoked pain & $/ 3=0-10 \times 2$ & $0-20$ \\
\hline Q11 + Q12 = Paresthesia/Dysesthesia & $/ 2=0-10 \times 2$ & $0-20$ \\
\hline
\end{tabular}

0 means no pain, but 10 means maximal pain imaginable.

Modified from the article of Bouhassira et al. (Pain 2004; 108: 248-57) [5].

1.408 is at or above 0 , it predicts neuropathic pain [37].

The DN4 is composed of 10 question items (yes: 1, no: 0 ) with 2 categories. First, from the interview of the patient, question 1 includes pain characteristics: (1) burning, (2) painful cold, and (3) electric shocks. Question 2 includes the presence of these combined symptoms: (4) tingling, (5) pins and needles, (6) numbness, and (7) itching. From the examination of the patient, question 3 includes the presence of hypoesthesia: (8) hypoesthesia to touch, and (9) hypoesthesia to pinprick. Question 4 is whether (10) the pain can be caused by or increased by brushing the painful area [39].

The LANSS pain scale includes a pain questionnaire and sensory testing. The pain questionnaire includes (1) unpleasant sensations such as pricking, tingling, or pins and needles (yes: 5, no: 0), (2) different appearance of the skin in the painful area, such as mottled or a red/pink appearance (yes: 5, no: 0), (3) abnormal sensitivity to touch (yes: 3, no: 0), (4) pain appearing suddenly and in bursts for no apparent reason, such as electric shocks, jumping, and bursting (yes: 2, no: 0), and (5) abnormal skin temperature change, such as feeling hot or a burning sensation (yes: 1, no: 0). The sensory testing for the presence of allodynia and an altered pinprick threshold includes (6) allodynia (yes: 5, no: 0 ) and (7) an altered pinprick threshold (yes: 3 , no: 0 ). The total score varies from 0 to 24 . If the score $<12$, neuropathic mechanisms are unlikely to be contributing to the patient's pain. If the score $\geq 12$, neuropathic mechanisms are likely to be contributing to the patient's pain [40].

The ID pain score includes 6 items scoring from -1 to 5 : (1) pain feeling like pins and needles (1/0), (2) hot/burning sensation (1/0), (3) numbness (1/0), (4) electric shocks (1/0), (5) worsening with touch $(1 / 0)$, and (6) pain limited to the joints $(-1 / 0)[41]$.

The painDETECT was developed to assess the neuropathic pain component in low back pain. It includes 3 items with (1) grading of pain (0: never, 1: hardly, 2: slightly, 3: moderately, 4: strongly, or 5: very strongly noticed), (2) the pain course pattern (0: persistent pain with slight fluctuations, -1 : persistent pain with pain attacks, +1 : persistent pain without pain between attacks, or +1 : persistent pain with pain between attacks), and (3) radiating pain $(+2$ : yes, or 0: no). The total score varies from 0 to 8 [42].

The NPSI is recommendable for evaluating the change of intensity of neuropathic pain before and after treatment. It includes positive symptoms and signs of neuropathic pain, including spontaneous pain (superficial burning and deep pain [squeezing and pressure], paresthesia or dysesthesia [pins/needles and tingling], as well as paroxysmal pain [electric shocks and stabbing]) and evoked pain (by brush- 
ing, pressure, and contact) (Table 4) [5].

\section{(1) Carbamazepine}

Carbamazepine (Tegretol ${ }^{\circledR}$ ) is still considered the firstline drug for the treatment of trigeminal neuralgia $[43,44]$. According to the White and Sweet diagnostic criteria of trigeminal neuralgia, the pain should be (1) paroxysmal, (2) provoked by light touch to the face, (3) confined to the trigeminal zone, and (4) unilateral, with (5) showing a normal clinical sensory test in the painful area [45].

In addition, according to the diagnostic criteria for classical and symptomatic trigeminal neuralgia of the International Classification of Headache Disorders (second edition) by the International Headache Society, classical trigeminal neuralgia shows (1) a paroxysmal attack of facial pain which last a few seconds to less than 2 minutes, affecting one or more divisions of the trigeminal nerve, (2) intense, sharp, superficial, or stabbing pain, or pain precipitated from trigger areas or by trigger factors, (3) stereotyped attacks in the individual patient, (4) no abnormal neurologic deficit, and (5) that it is not attributed to another disorder [46].

The metabolite of carbamazepine, carbamazepine-10,11epoxide, plays an important role for ADRs of carbamazepine. For the safer use of carbamazepine, (1) a monotherapy prescription (if possible), (2) adequate dose titration with monitoring plasma concentration, and (3) routine laboratory check-up, such as complete blood count and liver function test, are recommended [47].

\section{(2) Oxcarbazepine}

Oxcarbazepine (Trileptal ${ }^{\circledR}$ ) has been developed from carbamazepine through structural variation to avoid metabolites causing ADRs. However, oxcarbazepine is different from carbamazepine; (1) The mode of action of both drugs consists mainly of a blockade of sodium currents. However, in comparison to calcium channel blockade, oxcarbazepine or monohydroxy derivate expresses its effect via N-, P-, and/or R-type calcium currents, instead of the L-type calcium currents in carbamazepine. (2) It increases neither 5 -hydroxytriptamine (HT) release nor acetylcholine receptor blockade. (3) It does not inhibit the cytochrome P 450 enzymes, and it reduces the concentration of gamma-glutamyltransferase in the serum [48].

Oxcarbazepine and its metabolites are mostly excreted in the urine; an ability of renal clearance is important to determine the dose of administration. In patients with an impaired glomerular filtration rate below $30 \mathrm{~mL} / \mathrm{mo}$, (1) the daily dose should be halved to $4-5 \mathrm{mg} / \mathrm{kg}$ (almost 300 $\mathrm{mg} /$ day), (2) slower dose increases should be made, and (3) the dosing interval should be prolonged [48].

There is no evidence that oxcarbazepine is more effective than other medications in the treatment of diabetic neuropathy, radiculopathy, or postherpetic neuralgia [49]. First-line therapy for trigeminal neuralgia is still considered to be carbamazepine (600-1,200 mg/day), or if not, oxcarbazepine (600-1,800 mg/day) [4].

\section{(3) Gabapentin}

When we think of neuropathic pain, except trigeminal neuralgia, gabapentin and pregabalin are the first-line medications. Pain physicians consider these drugs to be neuropathic medications rather than anticonvulsants. Most medications are effective for specific symptoms and signs, not specific disorders or diseases. Gabapentin and/ or pregabalin are effective for positive symptoms of neuropathic pain in various disorders or diseases. The current consensus for pain management includes not only opioid and non-opioid analgesics, as major analgesics, but also anticonvulsants and antidepressants, as adjuvants. Chronic pain results from subacute pain followed by acute pain, due to extensive tissue damage or the presence of neuropathic pain. Therefore, evaluation of pain characteristics is essential at the beginning of pain treatment.

Gabapentinoids $\alpha_{2} \delta$ ligands, are derived from gamma aminobutyric acid (GABA) which blocks $\alpha_{2} \delta$ subunit-containing voltage-dependent calcium channels. Currently available gabapentinoids include gabapentin (Neurontin $^{\circledR}$ ), pregabalin (Lyrica ${ }^{\circledR}$ ), mirogabalin (Tarlige ${ }^{\circledR}$, DS-5565) used in Japan since 2019 [50], and gabapentin enacarbil $\left(\right.$ Horizant $^{\circledR}$, Regnite $^{\circledR}$ ) [51].

\section{(4) Pregabalin}

The next generation anticonvulsant for neuropathic pain, which followed gabapentin, is pregabalin. Pregabalin shows a stronger and longer action duration than gabapentin. However, it is necessary to change from gabapentin to pregabalin in patients with intractable neuropathic pain who are taking a high single dose of gabapentin (over $900 \mathrm{mg}$ ), which causes lower bioavailability (a high dose administration of oral gabapentin excretes directly into the stool). An increased frequency of oral intake with a different dose may be needed in prescriptions for both gabapentin and pregabalin for reducing pain and ADRs in initial titration (Table 5) [52].

The maximal dose recommended by the manufacture is $600 \mathrm{mg} /$ day; however, many patients with intractable neuropathic pain during the period of up-titration may need a higher dose to achieve adequate pain relief with tolerable ADRs [53]. 
Table 5. Different Titration Methods and Conversion of Gabapentin and Pregabalin for Patients with Intractable Pain Requiring a Rapid Dose Increase

\begin{tabular}{|c|c|c|c|c|c|c|c|c|c|c|c|c|c|c|}
\hline \multirow{3}{*}{ Day } & \multicolumn{8}{|c|}{ Gabapentin } & \multicolumn{6}{|c|}{ Pregabalin } \\
\hline & \multicolumn{3}{|c|}{ TID } & \multirow{2}{*}{$\begin{array}{l}\text { Total } \\
\text { daily } \\
\text { dose }\end{array}$} & \multicolumn{4}{|c|}{ QID } & \multicolumn{2}{|c|}{ BID } & \multirow{2}{*}{$\begin{array}{l}\text { Total } \\
\text { daily } \\
\text { dose }\end{array}$} & \multicolumn{3}{|c|}{ TID } \\
\hline & $7 \mathrm{~A}$ & $1 P$ & $7 P$ & & $7 \mathrm{~A}$ & $1 \mathrm{P}$ & $7 P$ & $11 P$ & $7 \mathrm{~A}$ & $7 \mathrm{P}$ & & $7 \mathrm{~A}$ & $3 P$ & $11 P$ \\
\hline 1 & - & - & 300 & 300 & - & - & - & 300 & 50 & 50 & 100 & 25 & 25 & 50 \\
\hline 2 & 300 & - & 300 & 600 & 100 & 100 & 100 & 300 & 75 & 75 & 150 & 50 & 50 & 50 \\
\hline 3 & 300 & 300 & 300 & 900 & 200 & 200 & 200 & 300 & 100 & 100 & 200 & 50 & 50 & 100 \\
\hline $4-6$ & 400 & 400 & 400 & 1,200 & 300 & 300 & 300 & 300 & 150 & 150 & 300 & 75 & 75 & 150 \\
\hline $7-10$ & 500 & 500 & 500 & 1,500 & 300 & 300 & 300 & 600 & 200 & 200 & 400 & 100 & 100 & 200 \\
\hline $11-14$ & 600 & 600 & 600 & 1,800 & 400 & 400 & 400 & 600 & 250 & 250 & 500 & 125 & 125 & 250 \\
\hline 15 & 800 & 800 & 800 & 2,400 & 600 & 600 & 600 & 600 & 300 & 300 & 600 & 150 & 150 & 300 \\
\hline
\end{tabular}

TID: ter in die; three times a day, QID: quarter in die; four times in a day, BID: bis in die; twice in a day, :- not available.

Modified from the article of Yang et al. (Korean J Anesthesiol 2013; 65: 48-54) [52].

(5) Mirogabalin

Both gabapentin and pregabalin have been known to act non-specifically on the $\alpha_{2} \delta-1$ and -2. Binding to the $\alpha_{2} \delta-1$ may produce analgesic effects, whereas binding to the $\alpha_{2} \delta$ 2 may be related to ADRs of the central nervous system, such as somnolence. Mirogabalin has been known to show more selective binding and slower dissociation to the $\alpha_{2} \delta-1$. Maximal plasma concertation after oral intake is achieved at around 1 hour. The plasma protein binding of mirogabalin is relatively low at $25 \%$. It is largely excreted in the urine $[54,55]$.

The equianalgesic dose of $30 \mathrm{mg} /$ day mirogabalin, for achieving over $50 \%$ pain relief (when the number needed to treat is around 5) in the treatment of diabetic peripheral neuropathy, is considered to be roughly $600 \mathrm{mg} /$ day of pregabalin, over $1,200 \mathrm{mg} /$ day of gabapentin, and $60 \mathrm{mg} /$ day of duloxetine. However, the ADRs of mirogabalin are lower than the other 3 drugs $[55,56]$.

\section{(6) Nefopam}

Nefopam (fenazocine, $\operatorname{Acupan}^{\circledR}$ ) is a non-opioid, nonsteroidal, centrally acting analgesic drug. The mechanism of analgesic action is similar to those of the triple neurotransmitters (serotonin, dopamine, and norepinephrine), uptake inhibitors (antipsychotics or antidepressants), and anticonvulsants. Therefore, it is suitable to use for neuropathic pain intravenously (continuous infusion), intramuscularly, or orally. It should be given intravenously, slowly, over 15-20 minutes, or intramuscularly, due to preventing known ADRs, such as cold sweating, dizziness, tachycardia, and drowsiness. It is also convenient to convert from intravenous medication during hospitalization into oral medication after discharge. The recommended dose of intravenous administration is $60-120 \mathrm{mg} /$ day, and oral administration for 3 to 6 times totaling $90-180 \mathrm{mg} /$ day [57].
(7) Antidepressants

Antidepressants have been used for the treatment of negative neuropathic pain, based on 6 mechanisms; (1) blockade of norepinephrine and serotonin, (2) blockade of sodium channels, (3) antagonism of NMDA glutamate receptors, (4) sympathetic blockade, (5) effects on visceral nerve fibers, and (6) effects on mood [58].

Antidepressants can be divided into first generation and second generation antidepressants. Nortriptyline has been chosen among the first generation antidepressants (tricyclic antidepressants, including amitriptyline, imipramine, and desipramine), due to the same strong analgesic effect with norepinephrine and serotonin reuptake inhibition, but lesser ADRs, such as anticholinergic effects (dry mouth), postural hypotension, and sedation. On the other hand, amitriptyline may be chosen due to its strong sedative effect in cases of insomnia (Table 6) [59].

\section{Emotional component of pain}

In addition to the sensory component of pain originating from actual tissue damage, the emotional component of pain from potential tissue damage should also be treated. While treating all sensory components of pain, including nociceptive and neuropathic pain, patients may complain of mysterious and vague generalized pain [59].

Available medications for the emotional component of pain are antipsychotics, anxiolytics, and antidepressants. There are 3 major neurotransmitters in the human brain: serotonin, norepinephrine, and dopamine. These neurotransmitters have their own functions: (1) serotonin is charged with the control of cognitive impulse and relaxation with memory, (2) norepinephrine has a relation to alertness, concentration, socialization, and energy, and (3) dopamine is deeply engaged in pleasure, motivation, reward, pain avoidance, and reality [59].

It is difficult to quantify each emotional item and to 
Table 6. Antidepressants Commonly Used to Treat Pain

\begin{tabular}{|c|c|c|c|c|c|c|c|c|}
\hline \multirow{2}{*}{ Antidepressant } & \multirow{2}{*}{ Analgesia } & \multicolumn{2}{|c|}{ Reuptake inhibition } & \multicolumn{4}{|c|}{ Adverse effects } & \multirow{2}{*}{$\begin{array}{l}\text { Elimination of half-life } \\
\text { of parent drug (hr) }\end{array}$} \\
\hline & & NE & SE & $\begin{array}{l}\text { Anticholinergic } \\
\text { effects }\end{array}$ & $\begin{array}{c}\text { Postural } \\
\text { hypotension }\end{array}$ & Sedation & $\begin{array}{c}\text { Cardiac } \\
\text { arrhythmia }\end{array}$ & \\
\hline Nortriptyline & +++ & ++ & ++ & ++ & + & + & +++ & $18-48$ \\
\hline Amitriptyline & +++ & ++ & ++ & +++ & +++ & +++ & +++ & $9-46$ \\
\hline Imipramine & +++ & ++ & ++ & +++ & +++ & ++ & +++ & $6-28$ \\
\hline Desipramine & ++ & +++ & 0 & + & ++ & + & +++ & $12-28$ \\
\hline Paroxetine & + & 0 & +++ & 0 & 0 & 0 & 0 & 21 \\
\hline Citalopram & + & 0 & +++ & 0 & 0 & 0 & 0 & 24 \\
\hline Venlafaxine & $?$ & ++ & +++ & 0 & 0 & 0 & 0 & 4 \\
\hline
\end{tabular}

NE: norepinephrine, SE: serotonin.

Modified from Max and Gilron (Antidepressants, muscle relaxants, and N-methyl-D-aspartate receptor antagonists. In: Bonica's Management of Pain. 3rd ed. Edited by Loeser JD; 2000, pp. 1710-26) [59].

supply a deficit in the clinical field. However, not only the sensory component, but also the emotional component should be considered in the treatment of pain.

\section{1) Antipsychotics}

Antipsychotics are effective in pain patients with positive psychotic symptoms (related to the mesolimbic pathway), not negative, affective, and cognitive symptoms (related to the mesocortical pathway) [59].

The antipsychotics can be divided into typical and atypical categories. The typical antipsychotics act on the $\mathrm{D}_{2}$ receptor; however, they produce extrapyramidal symptoms (dystonia, pseudo-parkinsonism, akathisia, and tardive dyskinesia) related to the nigrostriatal pathway and produce elevated serum prolactin levels.

In order to reduce the extrapyramidal symptoms and hyperprolactinemia, atypical antipsychotics have been developed through a decreased $\mathrm{D}_{2}$ receptor binding affinity, but an increased $5-\mathrm{HT}_{2 \mathrm{~A}}$ receptor binding effect. Certain atypical antipsychotics, such as risperidone, ziprasidone, sertindole, clozapine, olanzapine, zotepine, aripiprazole, and quetiapine, produce somnolence effect related to the $5-\mathrm{HT}_{2 \mathrm{~A}}$ receptor binding. On the contrary, sulpiride and amisulpride, like the typical antipsychotic haloperidol, do not produce somnolence. In addition, they increase the risk of metabolic syndromes, such as weight gain, diabetes, or dyslipidemia.

Antipsychotic equivalent oral doses, based on a daily oral dose of $100 \mathrm{mg}$ of chlorpromazine, are similar to $2 \mathrm{mg}$ (1-5 mg) of haloperidol, $100 \mathrm{mg}$ (30-150 mg) of clozapine, 2 $\mathrm{mg}(0.5-3 \mathrm{mg})$ of risperidone, $75 \mathrm{mg}$ of quetiapine, $5 \mathrm{mg}$ of olanzapine, and $7.5 \mathrm{mg}$ of aripiprazole [59].

\section{2) Anxiolytics}

If antipsychotics are called as major tranquilizers (neu- roleptics), anxiolytics are known as minor tranquilizers. Representative anxiolytic agents are GABAergics, such as benzodiazepines, barbiturates, and etifoxine.

The GABAA receptor consists of 5 subunits, two $\alpha_{(1-6)}$, two $\beta_{(1-3)}$, and one $\gamma_{(1-3)}$. Benzodiazepines are binding at the interfaces between the $\alpha_{1}$ and $\gamma_{2}$ subunit, and barbiturates bind at the interfaces between the $\alpha_{1}$ and $\beta_{2}$ subunit. Etifoxine directly acts on the $\beta_{2}$ or $\beta_{3}$ subunit, and indirectly activates the $18 \mathrm{kDa}$ translocator protein. It shows lesser ADRs of anterograde amnesia, sedation, impaired psychomotor performance, and withdrawal syndromes than those of benzodiazepines [58].

\section{Transition from intravenous patient-controlled analgesia into oral medication inpatients with intractable pain}

Patients with intractable pain need hospitalization for the investigation of the origin of the pain, the treatment of correctable causes, and the transition of analgesia from intravenous to oral medication for discharge. Available intravenous medications for analgesia are morphine, ketorolac, nefopam, dexmedetomidine, midazolam, steroids, and antiemetics (ramosetron, palonosetron, or ondansetron).

The first dose of each medication is determined by the origin and intensity of the pain. While escalating the daily dose of oral medication, the dose of intravenous medications with patient-controlled analgesia can be diluted with normal saline to half of the initial dose every 3 days.

After 4 cycles of dilution at 12 days, the transition to oral from intravenous medications is completed, using such medications as oral morphine, NSAIDs, nefopam, anxiolytics (antidepressant or antipsychotic), anticonvulsants, antidepressants, and steroids. Patients can be discharged from the hospital at 14 days after confirmation of having tolerable pain and ADRs. 


\section{CONCLUSIONS}

Most analgesics, except NSAIDs, ASA, or APAP, need the process of dose-up and -down titration. In order to achieve the 3 steps including reducing (1) night pain, (2) resting pain during the day, and (3) daily activity, the initial dose at night should be larger, even though the daily total dose is the same. Simultaneously, it is emphasized that the ADRs, such as orthostatic hypotension and dizziness, may develop at night. Dose-up titration is finished when both pain and ADRs are tolerable. When down-titration for discontinuing the analgesics begins, the dose at night should be the last to be reduced or discontinued.

According to the origin of the pain, an effective analgesic drug should be chosen. 1) For an unpleasant emotional experience, an antipsychotic, antidepressant, or anxiolytic is considered. 2) Various analgesics are needed for the control of an unpleasant sensory experience. (1) An NSAID, ASA, or APAP is effective for somatic nociceptive pain. (2) An opioid is helpful to relieve visceral nociceptive pain. (3) An anticonvulsant is used to control positive neuropathic pain. (4) On the contrary, an antidepressant should be chosen to relieve negative neuropathic pain.

Chronic pain, which has 2 or more pain components, needs combined therapy using these analgesics. Chronification of pain comes from a greater intensity of tissue damage or an existence of neuropathic pain. Therefore, chronic pain may include sensory component (nociceptive and/or neuropathic pain), as well as, emotional component which has developed from the beginning and/or may develop during the chronification of pain. In summary, various combination of analgesics, such as NSAIDs for somatic pain, opioids for visceral pain, anticonvulsants and/ or antidepressants for neuropathic pain, and antipsychotics and/or anti-anxiety drugs for emotional component, should be used properly and/or simultaneously. Polypharmacy is enhancing therapeutic analgesic effects while reducing ADRs. It is unreasonable to assume that opioids rather than NSAIDs are more effective or stronger for somatic pain.

When multiple analgesics are used for the treatment of pain (emotional and/or sensory components), the general and special condition of the patients and inter-analgesic medications should be considered.

\section{CONFLICT OF INTEREST}

No potential conflict of interest relevant to this article was reported.

\section{FUNDING}

This study was supported by a 2019 research grant from Pusan National University Yangsan Hospital.

\section{ORCID}

Kyung-Hoon Kim, https://orcid.org/0000-0003-3925-8917

Hyo-Jung Seo, https://orcid.org/0000-0002-7874-3758

Salahadin Abdi, https://orcid.org/0000-0002-3892-9208

Billy Huh, https://orcid.org/0000-0002-2825-9474

\section{REFERENCES}

1. Merskey H, Albe Fessard D, Bonica JJ, Carmon A, Dubner R, Kerr FWL, et al. Pain terms: a list with definitions and notes on usage. Recommended by the IASP Subcommittee on Taxonomy. Pain 1979; 6: 249-52.

2. Jensen TS, Baron R. Translation of symptoms and signs into mechanisms in neuropathic pain. Pain 2003; 102: 1-8.

3. Baron R, Maier C, Attal N, Binder A, Bouhassira D, Cruccu G, et al. Peripheral neuropathic pain: a mechanism-related organizing principle based on sensory profiles. Pain 2017; 158: 261-72.

4. Attal N, Fermanian C, Fermanian J, Lanteri-Minet M, Alchaar H, Bouhassira D. Neuropathic pain: are there distinct subtypes depending on the aetiology or anatomical lesion? Pain 2008; 138: 343-53.

5. Bouhassira D, Attal N, Fermanian J, Alchaar H, Gautron M, Masquelier E, et al. Development and validation of the neuropathic pain symptom inventory. Pain 2004; 108: 248-57.

6. Loeser JD, Treede RD. The Kyoto protocol of IASP basic pain terminology. Pain 2008; 137: 473-7.

7. Kallakuri S, Singh A, Chen C, Cavanaugh JM. Demonstration of substance $\mathrm{P}$, calcitonin gene-related peptide, and protein gene product 9.5 containing nerve fibers in human cervical facet joint capsules. Spine (Phila Pa 1976) 2004; 29: 1182-6.

8. Park SC, Kim KH. Effect of adding cervical facet joint injections in a multimodal treatment program for long-standing cervical myofascial pain syndrome with referral pain patterns of cervical facet joint syndrome. J Anesth 2012; 26: 73845 .

9. Kim TK, Kim KH, Kim CH, Shin SW, Kwon JY, Kim HK, et al. Percutaneous vertebroplasty and facet joint block. J Korean Med Sci 2005; 20: 1023-8.

10. Kim KH, Choi SH, Kim TK, Shin SW, Kim CH, Kim JI. Cervical facet joint injections in the neck and shoulder pain. J Korean Med Sci 2005; 20: 659-62.

11. Demondion X, Vidal C, Glaude E, Subocz L, Francke JP, Cotten $\mathrm{A}$. The posterior lumbar ramus: CT-anatomic correlation 
and propositions of new sites of infiltration. AJNR Am J Neuroradiol 2005 ; 26 : 706-10.

12. Danelich IM, Wright SS, Lose JM, Tefft BJ, Cicci JD, Reed BN. Safety of nonsteroidal antiinflammatory drugs in patients with cardiovascular disease. Pharmacotherapy 2015; 35: 520 35.

13. Handin RI. The history of antithrombotic therapy: the discovery of heparin, the vitamin $\mathrm{K}$ antagonists, and the utility of aspirin. Hematol Oncol Clin North Am 2016; 30: 987-93.

14. Smith DK, Demetriou T, Weber C. Aspirin for primary prevention: USPSTF recommendations for CVD and colorectal cancer. J Fam Pract 2019; 68: 146-51.

15. MacKintosh ML, Crosbie EJ. Prevention strategies in endometrial carcinoma. Curr Oncol Rep 2018; 20: 101.

16. Serrano D, Bonanni B, Brown K. Therapeutic cancer prevention: achievements and ongoing challenges - a focus on breast and colorectal cancer. Mol Oncol 2019; 13: 579-90.

17. Hurwitz LM, Joshu CE, Barber JR, Prizment AE, Vitolins MZ, Jones MR, et al. Aspirin and non-aspirin NSAID use and prostate cancer incidence, mortality, and case fatality in the atherosclerosis risk in communities study. Cancer Epidemiol Biomarkers Prev 2019; 28: 563-9.

18. Vane JR, Botting RM. The mechanism of action of aspirin. Thromb Res 2003; 110: 255-8.

19. Botting RM. Vane's discovery of the mechanism of action of aspirin changed our understanding of its clinical pharmacology. Pharmacol Rep 2010; 62: 518-25.

20. Tosco P, Lazzarato L. Mechanistic insights into cyclooxygenase irreversible inactivation by aspirin. ChemMedChem 2009; 4: 939-45.

21. Lucido MJ, Orlando BJ, Vecchio AJ, Malkowski MG. Crystal structure of aspirin-acetylated human cyclooxygenase-2: insight into the formation of products with reversed stereochemistry. Biochemistry 2016; 55: 1226-38.

22. Chiang N, Serhan CN. Aspirin triggers formation of antiinflammatory mediators: new mechanism for an old drug. Discov Med 2004; 4: 470-5.

23. Brune K, Renner B, Tiegs G. Acetaminophen/paracetamol: a history of errors, failures and false decisions. Eur J Pain 2015; 19: 953-65.

24. Graham GG, Davies MJ, Day RO, Mohamudally A, Scott KF. The modern pharmacology of paracetamol: therapeutic actions, mechanism of action, metabolism, toxicity and recent pharmacological findings. Inflammopharmacology 2013; 21: 201-32.

25. Candido KD, Perozo OJ, Knezevic NN. Pharmacology of acetaminophen, nonsteroidal antiinflammatory drugs, and steroid medications: implications for anesthesia or unique associated risks. Anesthesiol Clin 2017; 35: el45-62.

26. Schildknecht S, Daiber A, Ghisla S, Cohen RA, Bachschmid MM. Acetaminophen inhibits prostanoid synthesis by scavenging the PGHS-activator peroxynitrite. FASEB J 2008; 22:
215-24.

27. Aminoshariae A, Khan A. Acetaminophen: old drug, new issues. J Endod 2015; 41: 588-93.

28. Smith HS. Potential analgesic mechanisms of acetaminophen. Pain Physician 2009; 12: 269-80.

29. Sasaki F, Yokomizo T. The leukotriene receptors as therapeutic targets of inflammatory diseases. Int Immunol 2019; 31: 607-15.

30. Vyvey M. Steroids as pain relief adjuvants. Can Fam Physician 2010; 56: 1295-7.

31. Tager AM, Luster AD. BLT1 and BLT2: the leukotriene B(4) receptors. Prostaglandins Leukot Essent Fatty Acids 2003; 69: 123-34.

32. Pathan H, Williams J. Basic opioid pharmacology: an update. Br J Pain 2012; 6: 11-6.

33. Kreek MJ, Borg L, Ducat E, Ray B. Pharmacotherapy in the treatment of addiction: methadone. J Addict Dis 2010; 29: 200-16.

34. Ok HG, Kim SY, Lee SJ, Kim TK, Huh BK, Kim KH. Can oliceridine (TRV130), an ideal novel $\mu$ receptor $\mathrm{G}$ protein pathway selective ( $\mu$-GPS) modulator, provide analgesia without opioid-related adverse reactions? Korean J Pain 2018; 31: 739.

35. Jensen TS, Finnerup NB. Allodynia and hyperalgesia in neuropathic pain: clinical manifestations and mechanisms. Lancet Neurol 2014; 13: 924-35.

36. Bennett MI, Attal N, Backonja MM, Baron R, Bouhassira D, Freynhagen $\mathrm{R}$, et al. Using screening tools to identify neuropathic pain. Pain 2007; 127: 199-203.

37. Cruccu G, Truini A. Tools for assessing neuropathic pain. PLoS Med 2009; 6: e1000045.

38. Krause SJ, Backonja MM. Development of a neuropathic pain questionnaire. Clin J Pain 2003; 19: 306-14.

39. Bouhassira D, Attal N, Alchaar H, Boureau F, Brochet B, Bruxelle J, et al. Comparison of pain syndromes associated with nervous or somatic lesions and development of a new neuropathic pain diagnostic questionnaire (DN4). Pain 2005; 114: 29-36.

40. Bennett M. The LANSS Pain Scale: the Leeds assessment of neuropathic symptoms and signs. Pain 2001; 92: 147-57.

41. Portenoy R. Development and testing of a neuropathic pain screening questionnaire: ID Pain. Curr Med Res Opin 2006; 22: 1555-65.

42. Freynhagen R, Baron R, Gockel U, Tölle TR. painDETECT: a new screening questionnaire to identify neuropathic components in patients with back pain. Curr Med Res Opin 2006; 22: 1911-20.

43. Obermann M. Treatment options in trigeminal neuralgia. Ther Adv Neurol Disord 2010; 3: 107-15.

44. Di Stefano G, Truini A, Cruccu G. Current and innovative pharmacological options to treat typical and atypical trigeminal neuralgia. Drugs 2018; 78: 1433-42. 
45. Montano N, Conforti G, Di Bonaventura R, Meglio M, Fernandez E, Papacci F. Advances in diagnosis and treatment of trigeminal neuralgia. Ther Clin Risk Manag 2015; 11: 289-99.

46. Headache Classification Subcommittee of the International Headache Society. The international classification of headache disorders: 2nd edition. Cephalalgia 2004; 24 Suppl 1: 9-160.

47. Fricke-Galindo I, LLerena A, Jung-Cook H, López-López M. Carbamazepine adverse drug reactions. Expert Rev Clin Pharmacol 2018; 11: 705-18.

48. Schmidt D, Elger CE. What is the evidence that oxcarbazepine and carbamazepine are distinctly different antiepileptic drugs? Epilepsy Behav 2004; 5: 627-35.

49. Zhou M, Chen N, He L, Yang M, Zhu C, Wu F. Oxcarbazepine for neuropathic pain. Cochrane Database Syst Rev 2017; 12: CD007963.

50. Senderovich H, Jeyapragasan G. Is there a role for combined use of gabapentin and pregabalin in pain control? Too good to be true? Curr Med Res Opin 2018; 34: 677-82.

51. Kim ES, Deeks ED. Gabapentin enacarbil: a review in restless legs syndrome. Drugs 2016; 76: 879-87.

52. Yang JY, Lee WI, Shin WK, Kim CH, Baik SW, Kim KH. Administration of four different doses of gabapentin reduces awakening from breakthrough pain and adverse effects in outpatients with neuropathic pain during the initial titration. Korean J Anesthesiol 2013; 65: 48-54.

53. Serpell M, Latymer M, Almas M, Ortiz M, Parsons B, Prieto R. Neuropathic pain responds better to increased doses of pregabalin: an in-depth analysis of flexible-dose clinical trials. J Pain Res 2017; 10: 1769-76.

54. Domon Y, Arakawa N, Inoue T, Matsuda F, Takahashi M, Yamamura N, et al. Binding characteristics and analgesic effects of mirogabalin, a novel ligand for the $\alpha 2 \delta$ subunit of voltage-gated calcium channels. J Pharmacol Exp Ther 2018; 365: 573-82.

55. Javed S, Alam U, Malik RA. Mirogabalin and emerging therapies for diabetic neuropathy. J Pain Res 2018; 11: 1559-66.

56. Kim KH, Abdi S. Rediscovery of nefopam for the treatment of neuropathic pain. Korean J Pain 2014; 27: 103-11.

57. Max MB, Gilron IH. Antidepressants, muscle relaxants, and $\mathrm{N}$-methyl-D-aspartate receptor antagonists. In: Bonica's management of pain. 3rd ed. Edited by Loeser JD. Philadelphia (PA), Lippincott Williams \& Wilkins. 2000, pp 1710-26.

58. Choi YM, Kim KH. Etifoxine for pain patients with anxiety. Korean J Pain 2015; 28: 4-10.

59. Shin SW, Lee JS, Abdi S, Lee SJ, Kim KH. Antipsychotics for patients with pain. Korean J Pain 2019; 32: 3-11. 